\title{
Investigating Conceptions and Practice of Formative Assessment in Higher Education
}

\author{
Jean Laight ${ }^{1}$, Mandy Asghar ${ }^{2}$, Avril Aslett-Bentley ${ }^{1}$ \\ Leeds Metropolitan University ${ }^{1}$, York St John ${ }^{2}$, United Kingdom
}

\begin{abstract}
Building on previous collaborative research in a case study institution, this paper continues to investigate data from in-depth, semistructured interviews with 25 lecturers, spanning a wide range of disciplines and professions.

Findings suggest that the discourse of Formative Assessment is profoundly shaped by the cultural context of the courses and their communities of practice. It appears within disciplines that internal practices are also influenced by the context of the subject based environments. Consequently, understanding and approaches to Formative Assessment have been found to vary across the institution. Critical reflection on the work provides a basis for discussion of the implications for future developments in theory, research and practice.
\end{abstract}

\section{Introduction}

This paper builds on the work of a collaborative research team into how academics perceive and utilise formative assessment in practice [2]. It presents findings from a thematic analysis of data obtained from in-depth, semistructured interviews exploring the experiences of twenty five lecturers of their formative assessment practices at a university in the UK.

In the context of the UK, universities are strongly influenced by student dissatisfaction about feedback, derived largely from the results of recent national student surveys (NSS). The NSS is conducted at the end of the final year of study and has focused many lecturers' attention on the need to include formative assessment opportunities throughout in order to improve feedback processes and hence this aspect of their students' response. However, difficulties in doing this effectively are compounded by increased student numbers and modularisation of degrees which contributes to reduced opportunities to use formative assessment in practice [19].

\section{Rationale and concepts}

Formative assessment can be considered to be 'a slippery concept ', both theoretically and pragmatically, in relation to conceptual understandings and communities of practice [2]. A considerable debate exists in the literature about the nature of formative assessment and its role in Higher Education, acknowledging formative assessment to be a 'highly contested' issue [14]. For some, formative assessment is defined by its purpose, feedback, a process to improve both the learning and the teaching, a means to detect errors and for them subsequently to be corrected by the student. Problems arise where feedback associated with formative assessment often occurs too late after the learning and /or does not indicate to students how to improve, and therefore has little effect on their future performance. An integrated approach with timely effective feedback aligned to a feed forward approach is important to strengthen the link with the overall duration, depth and extent of learning. One definition of formative assessment encompasses this as “... all those activities undertaken by teachers and /or their students which provide information to be used as feedback to modify the teaching and learning activities in which they are engaged"' [5]. In contrast summative assessment normally occurs at the end of an episode of learning and is not necessarily accompanied by either qualitative feedback or a clearly identified way forward for student learning. Summative assessment can also be defined by its purpose, which is that of the measurement of learning that has taken place; a much more public purpose linked to student progression and ultimately classification of degrees.

Currently there is a strong drive internationally in Higher Education to support the value of formative assessment in enhancing student learning, although its practice is increasingly being integrated within other assessment terminologies. The term formative assessment can actually mean very different things. In assessment for learning, formative 
assessment, through both informal and formal feedback, is used as part of an overall assessment strategy, designed to increase student autonomy and enhance their ability to make their own judgements about their learning [10].

Formative assessment is therefore is a key, contemporary, sometimes controversial concept, with potential for enhancing student learning. It justifies further investigation and debate both in terms of perceptions and application in present practice with the potential for qualitative research to deepen understandings and develop practice [3],[20]. Formative assessment is an issue across this teaching-led case study university which used well has the potential to enhance the quality of the student experience. This research aimed to explore present practice and the views and opinions of the lecturers in the sample, to help develop a shared understanding, identify best practice and areas for improvement.

\section{Methodology}

A phenomenological methodology was used to explore in-depth the participants' experiences and practice of formative assessment. Phenomenology helps to address questions concerning human behaviour within the complex variables of society. It accepts that human beings are not reducible, but need to be understood from their individual and contextual points of view. Although phenomenological studies are not designed with the intention of producing generalizable findings, it is important to include a range of participants, both in terms of discipline and years of experience to enhance transferability. It is hoped that through a rich description of the findings the reader may find resonance with their own pedagogic practice.

The sample of fifteen participants (table 1) had varied years of teaching experience and were drawn from a variety of disciplines from across a British post-92 university that has 41,000 students. The university could be described as a teaching led, rather than a research intensive, institution. All participants were informed of the purpose of the study, assured of anonymity and confidentiality and voluntarily consented to participate.
Table 1. Participants' discipline and years of experience in Higher Education

\begin{tabular}{|l|l|}
\hline \multicolumn{2}{|l|}{ Youth and Community } \\
\hline Jill & $1-5$ \\
\hline Jess & $1-5$ \\
\hline Caroline & $11-15$ \\
\hline Brenda & $1-5$ \\
\hline Design & \multicolumn{2}{|l|}{} \\
\hline David & \\
\hline James & \\
\hline Samantha & \\
\hline Education & \\
\hline Amber & $6-10$ \\
\hline Freda & $6-10$ \\
\hline Barbara & $>20$ \\
\hline Sue & $>20$ \\
\hline ICT & \\
\hline Kate & $16-20$ \\
\hline Health & \\
\hline Claire & $1-5$ \\
\hline Curt & $>30$ \\
\hline Siobahn & $1-5$ \\
\hline
\end{tabular}

The initial analysis of a small sample of the data (five in-depth interviews) used Ashworth's phenomenological approach [2], [1]. The seven fractions comprising Project, Discourse, Spatiality, Temporality, Embodiment, Sociality and Selfhood were used as categories to represent the lifeworld experience of each the participants when analysing the data. Having analysed the data in this way and become familiar with it, a content analysis approach was subsequently used with the data as a whole. This changed focus allowed the data to lead the way and to establish new categories. The data set for this study is exceptionally large and so what is presented here is a selection of categories which were combined to generate the following two themes: Formative Assessment as a Pedagogic Practice and as a Community of Practice.

\section{Findings}

\subsection{Formative Assessment as a Pedagogic Practice}

Asking participants about their pedagogic practices seemed to problematise formative assessment and prompted some participants to ponder and reflect on what they thought it was or indeed was not. For many it seemed that this had become a critical reflective moment to consider what it was they were actually doing in their own 
pedagogic practice and why. Key aspects of this theme include a practice definition of formative assessment and the value of formative assessment

\subsection{Definitions}

A definition of formative assessment is bound up with opinions of whether or not the practice is a loose, informal affair or whether at the other extreme there is a need for a specific, recorded event that formally documents what has taken place in the teaching and learning incident. Or indeed, in some instances both. Whether participants described formal or informal formative assessment it was linked to temporality and movement evoking a sense of positivity and progress, whereas summative activities conjured up a rather more negative view for some participants.

James: Summative assessment then stifles wonder, speculation, enthusiasm, a sense of destination rather than the journey. Formative assessment is like, there is an element of it's always about, you know what you are moving towards; it's always about the future.

There are hints that speed is of the essence in giving feedback to Design students, therefore spoken, informal, formative feedback is a regular occurrence. By the nature of the discipline and the use of studio 'crits' in arts focused subjects, it might be expected that this would be a more accepted practice here than for others. However reflecting on the data there is a clear feeling of formative assessment as a weaving process that can occur in an ongoing manner throughout teaching and learning, and for students in teacher education, it is sometimes a process that relies on them picking up that feedback for themselves.

Freda: And you might not even say a word but gestures and "yes" and 'you know'...

Barbara: I think it is absolutely critical but as I say I think that if we use the loosest definition of formative assessment it should be happening all the time and it is about an ongoing dialogue

And for Claire in health that informality underpins a formative aspect to all practical classes: Maybe they are practicing a treatment technique and I will say "no, your hand needs to be here, or feel this, or touch this or move it this way".

Formal formative events were also cited with James discussing formalised assessments, or what he describes as "upper case F and A". An air of seriousness pervaded these descriptions of opportunities that participants felt could make crucial differences to student learning. They often consisted of short essays submitted early in the semester or presentations and were often positioned early in a student's higher education experience.

Curt: I think of that because of the position of $1^{\text {st }}$ year relative to students' experience, so they are coming from school and it is their first exposure to higher education-I think it is probably more important that they have a sound...almost structured, formative assessment programme.

Participants in the study grappled with the concept of formative assessment and marks. The idea that formative assessment does not contribute to the academic credit awarded to a student seemed almost too much for some to forgo, with a clear need in some cases to assign a piece of work a number. This confusion over the role that marks can play in feedback presented, for some, a sense of discomfort with participants telling students "if it had been marked, it would have been given X percent”. In other instances, because a piece of work was completed early in the module and given a summative mark, it was also considered to be formative as it might have the power to influence future learning. Little consideration seemed to be given as to how important it is that formative opportunities, classically, are about improving existing work rather than exclusively future work.

Brenda: Yes it does carry a mark, in which case I know it is considered summative assessment, but it's early on in the module and I consider it formative assessment as well.

Jill: I mean I think the main one is that whole thing around the mark - should it have a mark, should it not have a mark? If it does have a mark is it formative or is it summative? I think that just because something has a mark, it doesn't necessarily make it a summative assessment, you know I think it can still be formative and carry a mark. 
Siobhan: I don't mark it, but it's something they have to do and then I go through their presentation and their presentation skills and what I thought was good, bad and indifferent and what mark I would have given it out of ten.

There were participants who were concerned about students' willingness to engage with formative opportunities and felt that incentivising this by providing a mark would be key to participation.

Jess: We spend so much time giving all this detailed feedback and all students all seem to be interested in actually is their mark

A contrasting view presents the dilemma then, that students are often felt to be so focused on marks that qualitative feedback is ignored and therefore it is much more important to concentrate on qualitative rather than quantitative feedback.

David : We have preliminary crits, as we call them, where we, you know respond to the student work by giving feedback and it's either written or verbal, because we don't necessarily give marks we kind of give feedback.

Claire: For me, it is not assigning a number or a grade or a percentage. It's not giving it that "you've got a 48\% or a 49\%". For me it is a combination of giving useful, critical comments, perhaps on how someone could do better or change.

In both defining formative assessment and unpacking how it differs from summative assessment there was much disagreement. At times participants' understandings were implicit rather than explicit where some who confused the terms 'formative' and 'summative' usually indicated an awareness of the typical processes, even if the terminology afforded misconceptions. Some of our participants for whom exams are used as summative assessment explained how they have helped students to succeed by encouraging them to improve in different ways but without formally recognising this process as formative assessment.

There was often, too, a contradiction in the way formative assessment activities were carried out, with a lot of 'I' and 'we' do 'this' or 'that', implying tutor-led activities where "we" meant tutors exclusive of students. But yet the same people went on to describe how important it is to provide opportunities for students to peer assess each other in informal ways. This included employers and significant others who would provide feedback to the students, with participants recognising how important this was to students' future employment. It was not that this did not occur, but that despite the importance placed on it, it was overshadowed by a dominance of tutor-led activities.

\subsection{Value}

Tutors were engaged in formative assessment activities with their students because it was viewed as having value for learning. This was underpinned by the desire to give students confidence and to provide them with a supportive and safe environment. Whilst feedback featured strongly throughout our conversations, the power of formative assessment in the development of self-efficacy was an aspect implicit through many of the views of the participants

Amber : Yes it is the thought of it, yes the thought of it, but once they have done it, and usually doing that debriefing period afterwards, when they have got their written feedback, that typically their reaction is of relief.

Feed-forward is not explicit here, but it is possible to see how this could be linked to selfefficacy. This example, from Amber, demonstrates a student-centred focus and a concern for the learning process, which appears to reflect her discipline. All the participants from teacher education displayed a high level of understanding of assessment and the need to promote student self efficacy.

Caroline: I mean I was a teacher for many years as well, so training is kind of a real interest to me and not just imparting skills because it raises so much sort of self esteem and self confidence in students when they get involved in it.

Caroline provides a similar perspective and her previous experience in teaching may have increased her perception of assessment and enabled her to readily develop a student-centred approach to assessment. She demonstrates an interest in enabling self-efficacy to support achievement in her current discipline of youth 
and community work. In a similar way Sue, also from education, extends this further, focusing on the development of the autonomous student, who should be capable of self-evaluation.

Sue: You can't develop if you don't have some self-confidence. So it is this nurturing. I was an infant teacher. So it's nurturing the learner so that they become skills to be able to make their own judgment and work in new ways...

For the design tutors, the culture of their daily pedagogic practice was one of consistently engaging in feedback. There was a sense of individuals in a community sharing the feedback process with everyone moving forwards together. This integrated feedback approach was not exclusive to design but also surfaced in the teacher education interviews. This raises the importance of how context impacts on the types of formative activities that take place. For Art there's the studio, for health there's the clinical environment and for education there's the classroom whereas other subjects are not so impinged upon by an environmental context and this may influence pedagogic practice. Importantly also in health and education there are significant others who provide students with ongoing feedback. There are also professional bodies overseeing assessment processes who are concerned that higher education has a public responsibility to ensure that the students graduating become competent professionals.

James: The studio stuff, you know you could be there with the students in a workshop or in the studio or whatever talking about what they have done, talking about this drawing and so on and there's a kind of immediate feedback link, you know, and they could say well, what if I try this then, and that's sort of learning in action and all that sort of thing.

James illustrates informal and spontaneous feedback and identifies the importance of timing and, in particular, the speed that is necessary in the practical setting for his discipline. The need for immediate formative feedback that prompts change was noted by some of the other participants as important, especially when activities of a practical nature were involved. Feedback on the other hand was formalised on occasion in specific events but as with the other examples, the majority of our participants used these opportunities to direct students in their forward learning.

David: So they are kind of creating in a sense with a panel who then gives feedback and then there are things like what we call red letter days where we summarise like the creation of a student and if there's a problem they get a red letter which says, you know, identifies what they ought to be doing, so like formatively and we have 3 red letter days within the academic year.

Formative assessment has value in that it provides students with a safety net, a chance to explore and to make mistakes. In many instances students were encouraged to experiment without fear of failure.

Kate: From that Level 1 example, absolutely vital, really. And part of it is a reality check for the students, and really checking, you know, letting them ... giving them the chance to make mistakes that are not going to be penalised in the assessment.

Like Kate, some participants are aware of the expectations that students who are new to Higher Education have. Many noted that students have been used to presenting several draft assignments to their previous tutors and teachers in Further Education or at school. Without this interim step, some students feel out of their depth and vulnerable to failure. Some participants provided students with extra written assignments, usually about 500 words in length, which are formatively assessed, in order to provide the interim support they need. Although this is extra work for the participants, they believed that this process helps transition to Higher Education.

Formative assessment as a pedagogic practice presents a mixed view across our participants influenced by years of higher education experience, confidence as tutors, and the context of the discipline being taught. More participants demonstrated a commonality of view about the nature of its value for learning, than did about how it should be practiced.

Freda from Education on staff identity: $O h, I$ love it. I mean this job, the job I do here. I just, I mean, I thought I loved teaching. I thought I loved school, but this, I get such a real buzz of being with these people and seeing them achieve and it is very rewarding. 
Many participants shared Freda's view. They feel happier working in Higher Education than they did working in their previous employment. Many have come from areas of discipline which they now consolidate in their teaching of it, so they are confident in their discipline and have also, in many cases, become confident in their teaching of it. Some, however, feel that they are still getting their bearings in teaching in Higher Education, even though they are competent practitioners in their disciplines.

Kate from ICT on communities of practice: We work in a team to make sure everybody understands the criteria and the marking and is OK with the timescales and make sure that, you know, the timescales all fit in. And if there is anybody who, say, can't manage to mark the formative because they are teaching... then we will work as a team to work through that and mark each others and that sort of thing.

Being part of a team was important to most participants. Sometimes, it was reflected in how they related well to the other members of the course team, as seen in Kate's comments, and sometimes they referred to the wider Higher Education community. Many related their achievement in bringing students into communities of practice within their discipline areas.

\section{Discussion}

These extracts provide some insight to the overall findings, suggesting that the discourse of formative assessment is profoundly shaped by the cultural context of the courses and their communities of practice. According to Wenger, the initial characteristic of any community of practice is mutual engagement [18]. It is important, therefore, for students to be on the same 'wavelength' as their tutors and the purpose of the course in order to begin engagement. Engagement with the course may have initial difficulties, particularly when students are new to university life and are learning how to become a student and all that that entails, as well as being part of a specific community within a course. However, the course design, the desire to study on that course, committed tutors and peers who share the same focus should all contribute to enabling the new student to engage with the course. Evidenced through the data is the participants' intention to use formative feedback to engage students and subsequently to deepen their understanding of practice, both on the course and also within their community. Once students understand that formative feedback is there to enhance their work rather than as a tool to judge or label them, then they are able to trust tutors to give feedback in that cultural context to improve their practice and secure their place within that community.

Formative feedback and feed-forward should be built into normal practices of the learning and teaching process [11]. They also recognise the value of peer assessment and that feedback can be provided in this way. Using peer assessed feedback consolidates the notion of a community of practice in which the power is distributed. Nicol and Macfarlane-Dick argue that students should be encouraged to use formative assessment and feedback to empower them as self-regulated learners. Furthermore, they believe that students' self-esteem and motivational beliefs can be affected by feedback. Although it is the tutors who use feedback as information to inform their teaching, peer-assessed feedback is a useful tool in employing dialogue to enable further disclosure, improving trust and engagement to create an effective community of practice [11].

Nicol believes that learning groups and communities can be enhanced by developing good assessment and feedback practices [12]. He suggests that, to improve the quality of experience of students in their first year of learning in higher education, it would be helpful to encourage social bonding and develop learning communities. He also proposes that the emphasis should not be on learner engagement, but on learner empowerment, which would assist both academic and social engagement. Learner empowerment could subsequently fuel confidence and would therefore encourage understanding and trust of both peers and the tutors. In this way, mutual engagement within the community of practice may be allowed to grow.

Once a mutual engagement has been established, enabled through developing a shared practice, Wenger explains that the next key dimension is the negotiation of a joint enterprise. Keeping the community together depends upon its participants, and communities of practice depend on the wider ranging historical, social, cultural and institutional contexts [18]. Even when external conditions are imposed, such as those from regulatory bodies or the university regulations themselves, participants of a 
community of practice will respond to these, and it is how they respond which determines ownership. There is, therefore, a sense of community, in spite of outside influences, whether they are positive or negative. Joint enterprise accommodates the notion of mutual accountability, signifying what is important and what is not. Throughout the university, the education of students to perform at a high level to achieve a degree of a high standard is the overarching driver. It may therefore be stated that the university in its entirety is in fact a community of practice. However, if that were the case, then participants would have similar experiences, opinions and perceptions of formative assessment. Because they do not share these exactly, and because there is variance from discipline to discipline, are we to assume that the reason for this is that disciplines have shaped the communities of practice, as Wenger suggests, by shaping them through strong, shared mutuality?

The notion of mutual accountability also suggests that tutors are accountable, as well as students, in the assessment process. Formative assessment is a key factor in the process, and students expect to be given appropriate feedback, according to the data, to enable them to deepen their understanding and improve their work. Although some internal practices are also influenced by broader professional and regulatory environments, as well as the university regulations, for some participants, formative assessment is an intuitive aspect of their teaching. They may not be aware of the correct terminology, often confusing formative with summative assessment, but they do know that it is important to maintain a dialogue with students to enable them to improve.

Some participants, notably those whose disciplines are ultimately regulated by a professional body, appear to be more aware of the assessment processes. For them, it is important that their students are well prepared for a variety of standards they will need to meet and that they are prepared, not only for written assessment purposes, but also for assessed placements. Participants from these areas of discipline, that is, Health and Education, appear to understand the purpose and terminology of formative assessment very well. Not only are these participants preparing their students for independent assessment criteria as well as academic university assessment criteria, they are preparing them for what is to be a specific professional community of practice. Do these participants, therefore, have a deeper understanding of the nature of mutual accountability? Is there a greater awareness of joint enterprise occurring when the community of practice is regulated by a specific body?

Wenger cites the third characteristic of a community of practice to be its shared repertoire [18]. This includes particular vocabulary, technical terms, concepts, rules and routines which apply solely to that community. However, participants for whom there is no regulatory board other than the university also see their students as preparing for a specific community of practice. The difference between these two types of participants is generally that the latter use formative assessment intuitively and do not necessarily use or fully understand the terminology. If formative assessment is therefore happening, then is it important that it is recognised and acknowledged? If the process is working in spite of a lack of understanding, is this a problem? To evidence whether or not the process is working, then further research would need to be undertaken to assess success in the summative assessment, namely the students' degree attainment. Yet it would be difficult to prove that intuitive assessment such as this works, works better or is less efficient than its more formal exposition.

The most important driver in opposing the solely intuitive approach to formative assessment must be the need for success in national student surveys. It may be argued, from this research, that participants who do understand and use and recognise assessment appropriately do so primarily to enable students to improve and succeed. They did not feel the need to steer formative assessment as an end in itself; they welcomed the use of formative assessment to punctuate their engagement with students to enable improvement in all areas of their courses. However, because these participants are so aware of the benefits and the correct uses and manifestations of formative assessment, they may also presume that their students are similarly aware of it to the same degree. Many students new to HE do not recognise when this is taking place, nor do they necessarily acknowledge the effort and benefit associated with the assessment and feedback they have received when they fill in the national student surveys referring to it.

Participants generally feel that relationships are at the heart of their teaching, which enhances the reciprocal nature of formative assessment. Some recognise that it is not only advice from tutors which is helpful for the student, but also advice 
from peers. Again, the empowering presence of specific communities of practice supports this notion, in which a shared language and shared values may be discussed to enhance students' learning. It is also recognised that spoken, immediate feedback is valued by both tutors and students as an ongoing source of useful formative feedback. Perhaps the flow of this is so beneficial and successful that it is not later analysed and recognised as formative assessment and feedback. Do tutors need to be more explicit when using formative assessment? Do students really know what it is and can they recognise it? Is there a significant difference between communities of academic practice and communities of disciplinary practice which need to be addressed in their variable approaches to formative assessment?

\section{Conclusion}

The understanding of and the approaches to formative assessment have been found to vary across the institution, in keeping with 'signature pedagogies' [15]. There are interesting comparisons to be made with the work of other researchers in this field [10]. Critical reflection on this piece of work raises debate on how to meet the challenges posed for the future development of formative assessment in relation to theoretical frameworks, research investigations and communities of academic practice.

\section{References}

[1] Ashworth, P., 2003, The Phenomenology of the Lifeworld and Social Psychology, Social Psychological Review vol5, no 1, p. 18-34.

[2] Asghar, A., Laight J., and Aslett-Bentley, 2008, Discursive Commnuties and Local Practices Formative Assessment as a Local Practice SRHE Conference Presentation, Liverpool.

[3] Asghar, A., 2010, Reciprocal Peer Coaching as a Formative Assessment strategy for first year students, Assessment and Evaluation in Higher Education vol. 35, no 4, 403-417.

[4] Bandura, A., 1997, Self-Efficacy The Exercise of Control, W H Freeman \& Co.

[5] Black, P., and Wiliam D., 2006, Developing a Theory of Formative Assessment. Assessment and Learning Sage Publications London.
[6] Cooper, B., Charlton M., Soosay M., and Dean L., 2008, Crossing Boundaries: Collaboration in Action. SRHE Conference Presentation, Liverpool.

[7] Ecclestone, K., and Pryor J., 2003, Learning Careers or Assessment Careers? The Impact of Assessment Systems on Learning. British Educational Research Journal Vol. 29, no 4, 471-488.

[8] Gauntlett, 2007, Literature Review on Formative Assessment. Middlesex University.

[9] James, M., 2006, Assessment Teaching and Theories of Learning. Assessment and Learning Sage Publications London.

[10] McDowell, 2006, Assessment for Learning; Current practice exemplars for the Centre for Excellence in Teaching and Learning, Northumbria University.

[11] Nicol, D., and Macfarlane-Dick D., 2004 Rethinking Formative Assessment in HE: a theoretical model and seven principles of good feedback practice. Higher Education Academy.

[12] Nicol, D., 2008, Transforming Assessment and Feedback: Enhancing Integration and Empowerment in the First Year. Quality Assurance Agency, Scotland.

[13] Nolan, J., and Mayfield W., 2008 Formative Assessment as an Object of Enquiry, SRHE Conference Presentation, Liverpool.

[14] Race, P., 2007, The lecturer's toolkit: A practical guide to teaching and assessment, Routledge, Abingdon UK.

[15] Shulman, L., 2005, Signature pedagogies in the professions, Deadalus Summer 2005 52-59.

[16] Taras, M., 2003, To Feedback or Not to Feed back in Student Self-Assesment. Assessment and Evaluation in Higher Education 28(5) 549-65.

[17] Taras, M., 2008, Summative and formative assessment: Perceptions and realities. Active Learning Higher Education 9 172-189.

[18] Wenger, E., 2008, Communities of Practice. Cambridge University Press.

[19] Yorke, M., 2001, Formative Assessment and its Relevance to Retention. Higher Education Research and Development vol20, no 2 115-126.

[20] Yorke, M., 2003, Formative assessment in Higher education: move towards theory and the enhancement of pedagogic practice. Higher Education 45 477-501. 